\title{
INTRA-ARTICULAR ARTHRODESIS OF THE DISINTEGRATED TUBERCULOUS HIP JOINT
}

\author{
D. W. C. Gawne and G. S. Fung, Singapore \\ From the Orthopaedic Department of the General Hospital, Singapore
}

The term " disintegrated tuberculous hip" refers to a completely disorganised hip joint, in which the acetabulum and the head and neck of the femur have been destroyed by a tuberculous process-a hip in which conservative treatment offers no possibility of restoration of mobility and little hope of restoration of stability (Figs. 1 and 2).

Experience has shown that only sound bony fusion of these joints guarantees a cure. The operation is done in two stages. The first stage may have to be subdivided into two procedures: drainage of the diseased joint (Girdlestone and Somerville 1952): and

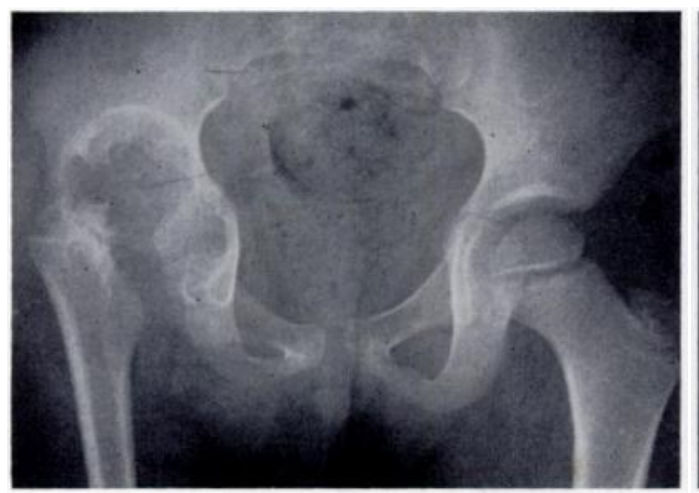

Fig. 1

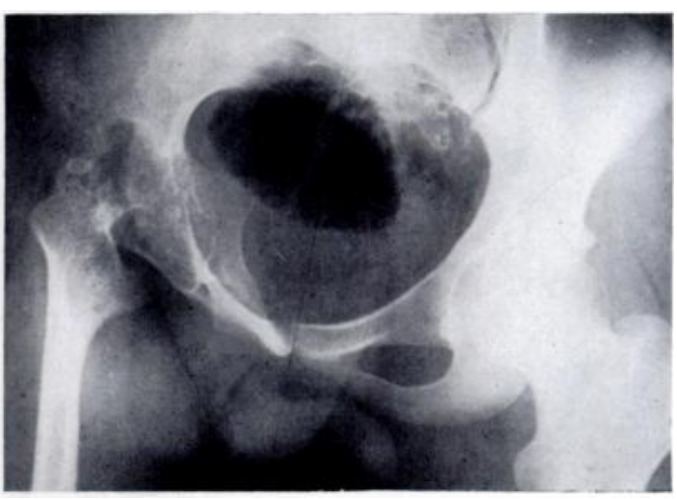

FIG. 2

Radiographs showing "disintegrated hips." Figure 1-The pelvis of a boy of ten, showing extensive destruction of the right hip. The disease had been active for four years and an abscess was present. Figure 2-The pelvis of a youth of nineteen, showing destruction of the right hip. The process had been going on for eleven years.

excision of the joint, shaping the greater trochanter to fit into a reamed acetabulum, and holding the hip widely abducted in plaster until fusion occurs (Abbott and Fischer 1931). The second stage consists in high femoral osteotomy, with ischio-femoral graft (Brittain 1942).

\section{MATERIAL}

Over the past four years fifty-eight patients with disintegrated tuberculous hips have been operated upon without mortality. No radical operation was done in children under six years of age, because the fate of the epiphyses was unknown. The first twenty-five patients, who were operated on between June 1954 and October 1956, have been selected for review because all have been under observation for at least two years (Table I). Twenty-two of the patients were Chinese; the rest were Malayan.

No patient had received any treatment in hospital during the first two years of the disease, and two had not even had any domiciliary treatment. The rest were treated intermittently for three to ten years before surgery was undertaken. Eighteen patients came to operation three to ten years from the onset of the disease; one after sixteen years. One patient had had no treatment whatever for fifteen years before operation. 
The patients were all seriously disabled. All had pain and deformity; none could attend school or work, or walk any distance. All had, or had had, pulmonary lesions. Some had discharging sinuses and other complications (Table II). Fifteen were completely bedridden.

It appears that in patients with multiple lesions the elimination of a gross hip lesion tipped the balance in favour of recovery.

TABLE I

Age and Sex Distribution:

TWenty-five Disintegrated Tuberculous Hips

\begin{tabular}{|c|c|c:c|}
\hline $\begin{array}{c}\text { Age } \\
(\text { years })\end{array}$ & Female & Male & Total \\
\hdashline $6-8$ & 3 & 3 & 6 \\
$9-11$ & 4 & 2 & 6 \\
$12-14$ & 1 & 3 & 4 \\
$15-17$ & 1 & 4 & 5 \\
$18-20$ & 3 & 1 & 4 \\
\hline Total & 12 & 13 & 25 \\
\hline
\end{tabular}

TABLE II

Site AND Activity of Associated Tuberculous Lesions

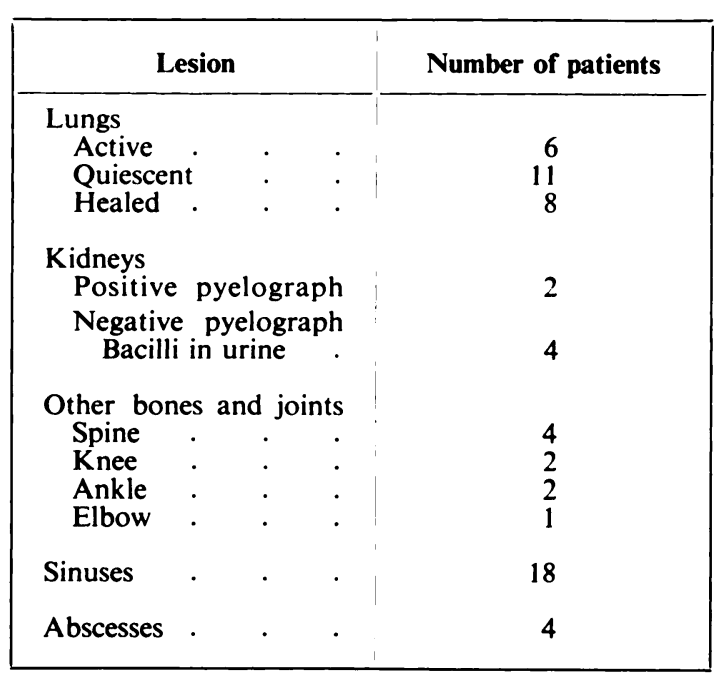

\section{MANAGEMENT}

The decision to carry out the operative procedure in two or three stages, and the determination of the interval between stages, are based on consideration of general fitness, state of nutrition, on the level of haemoglobin and on the erythrocyte sedimentation rate.

The patients are treated for two or three weeks in a bivalved hip spica on a Jones frame.

Treatment with streptomycin, isoniazid and para-aminosalicylic acid is started. Protein and vitamin deficiencies are corrected. A haemoglobin level of at least 80 per cent is required before operation, and if necessary this is achieved by blood transfusion. If the patient has a rising erythrocyte sedimentation rate operation is postponed. Adequate rest is important, and sedation is given when necessary. 


\section{TECHNIQUE OF OPERATION}

Anaesthesia-Nitrous oxide and oxygen given by endotracheal tube, with sedatives and relaxants given intravenously, seems to be the best anaesthetic for these patients, all of whom have or have had pulmonary lesions. Blood transfusion may be necessary, especially during excision of the hip.

Drainage - This is done only when free pus is found by aspiration. A lateral approach, between gluteus maximus and tensor fasciae latae with division of gluteus medius, or anterior displacement of gluteus medius and vastus lateralis, is used. As much capsule is excised as will give free drainage. Pus, loose debris, and any bony excrescence that will obstruct drainage are removed. The cavity is packed with gauze impregnated with bismuth iodoform paraffin paste. The skin is loosely sutured. Seven to ten days

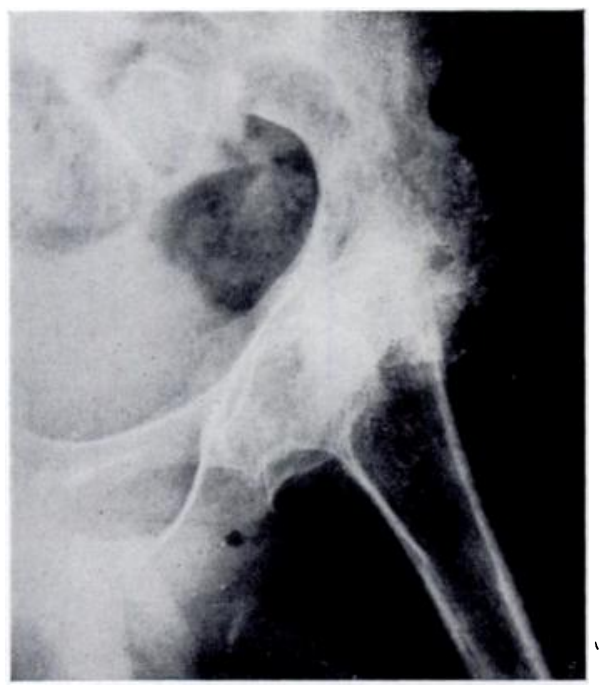

Fig. 3

Fusion proceeding after excision of the disintegrated left hip of a youth of seventeen. later the gauze is removed in the theatre. If the wound requires further drainage it is repacked; if it is satisfactory, as judged by a lack of pus and quiescent granulation, excision is undertaken.

Fifteen patients had sinuses at the time of operation. Three had a large abscess in the joint, requiring preliminary drainage. The capsule had been penetrated in all, in its posterior-superior portion in ten and in its inferior-medial portion in five cases. One patient with a large abscess cavity had to have the joint drained through an inferior approach. Excision-Fibrous tissue, cartilage, debris, and any bone which seems affected are excised. The criterion of an effective removal is a reduction of haemorrhage. Bleeding is sometimes profuse at the start of the excision. As normal tissue is exposed there is a capillary ooze, which can be controlled by gauze swabs. It is considered important that no abnormal tissue or any foreign material should be left in the wound. Haemorrhage from small arteries

is stopped by applying fine haemostats, which are left in position for a few minutes while the rest of the dissection goes on. Ligatures and cautery are not used; we have had no patient with delayed or secondary haemorrhage. The whole of the capsule and the whole of the acetabular cartilage are removed. The acetabular notch, particularly, requires the closest attention, for recurrence usually occurs in the infero-medial part of the joint around the basal attachment of the ligamentum teres. It is an advantage to remove the overhanging acetabular rim which forms the notch, because a better fit between femur and acetabulum can then be obtained with less abduction of the femur. This facilitates the osteotomy stage. The greater trochanter is shaped to fit the acetabulum, then the basal portion of the disintegrated femoral neck is removed and tuberculous tissue is excised down to the lesser trochanter. The lesser trochanter requires particular attention. It is often necessary to expose the insertion of iliopsoas because a small pocket of pus may be present here. This area must be in a healthy state because it is the site for the later osteotomy. When the excision is complete the leg is brought into wide abduction, so that the greater trochanter fits deeply into the acetabulum. The adductor muscles will ensure stability (Abbott and Lucas 1954). In closure the gluteus medius is drawn down over the acetabulum and trochanter, and sutured as low as possible to the vastus lateralis. The gluteus maximus and tensor fasciae latae are lightly approximated, as are the vastus lateralis and gluteus maximus, as few sutures as possible being used. After skin closure, a firm pressure bandage is applied, and the leg is put in a plaster-of-Paris spica with the hip widely abducted. The position is confirmed by radiographs. When the patient's 
general condition is good, callus is seen four to six weeks after excision. As a rule union is strong enough to stand osteotomy between the second and third month (Fig. 3). Delay in formation of callus indicates that the primary excision was incomplete. The shortest time between excision and osteotomy was six weeks, the longest eight months. With experience, the excisions have become more complete, and the interval is now eight weeks on an average.

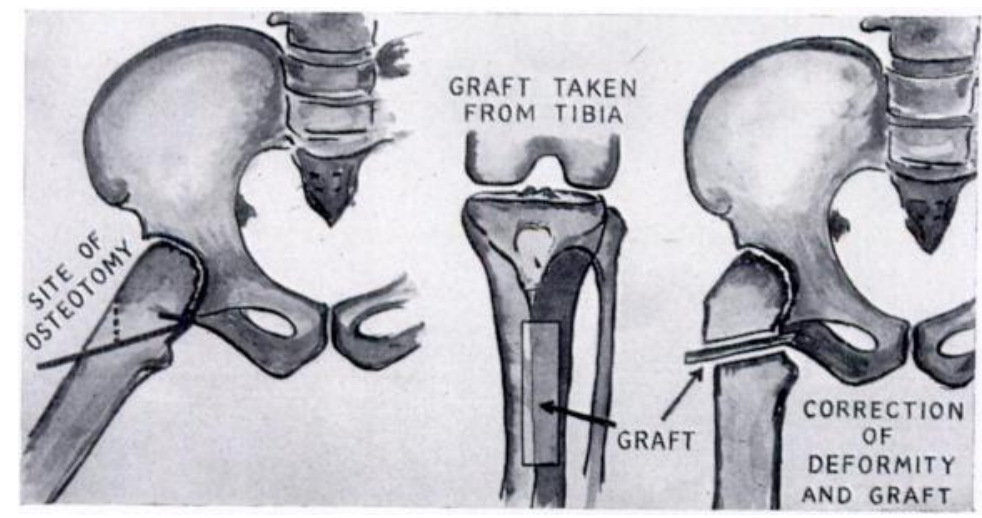

Fig. 4

Diagram showing the stages of osteotomy and graft. Note the obliquity of the line of bone section.

Osteotomy-This is done when radiographs show good callus and when there is no mobility. The patient is put on an orthopaedic table. The lower part of the original incision is used, and the bone is divided with a little elevation medially at the level of the lower margin of the acetabulum. The leg is adducted to the neutral position, and a spatula is introduced through the osteotomy site to touch the base of pubis or ischium. A chisel, the width of the diameter of the femur, is directed along the spatula and driven into the bone, bevel down. Another chisel, bevel up, in apposition with the first, is driven in alongside. A graft is cut from the upper tibial shaft of the healthy leg, of a length equal to the buried portion of the chisel, and of the same width as the chisel. This is bevelled at one end, and is put in place of the lower chisel, cortex uppermost. The upper chisel is now removed and the graft is hammered home and trimmed off (Fig. 4).

A cavity is sometimes left between the trochanter and the acetabulum, particularly when the excision has been followed by wide abduction (Fig. 5). It should be curetted and packed with bone chips after the graft has been inserted.

The traction on the leg is released until the distal end of the femur is in firm apposition to the graft. The femur is displaced medially so that the line of weight bearing is as near midline as possible. The wound

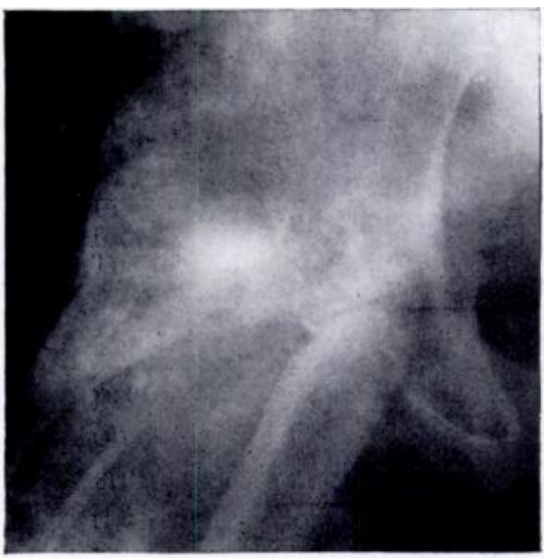

Fig. 5

Radiograph of the right hip of a girl of eighteen, showing cavity formed between the trochanteric fragment and the acetabulum after osteotomy. is closed and the plaster-of-Paris applied to include the opposite leg as far as the knee.

If the excision of diseased tissue has been incomplete, union will not occur and progress to the osteotomy stage is thus halted. It is therefore safe to assume that there is no possibility of osteotomy through diseased bone being done. A breakdown after excision occurred once and necessitated further excision. 
The graft is not essential but in our experience leads to earlier and more sound union. The position of the leg after osteotomy-The position of flexion is adopted in children over ten years of age and in adults. For a child of ten the position is one of 10 degrees of flexion; a degree is added for each year of age, up to a maximum of 30 degrees. No attempt is made to compensate for the shortening by abduction. A maximum of 10 to 15 degrees of abduction is allowed between the ages of six and ten. In patients over fifteen the leg is kept parallel to the body axis. Shortening is corrected by a raised shoe. When the leg is in a relatively normal position patients can walk with more comfort and less limp and they do not develop backache. If an attempt is made to compensate for shortening of the leg by abduction backache makes an early appearance. The leg is laterally rotated 5 degrees. Children under ten compensate by pelvic tilt for the abduction allowed and retain a fully mobile back. In addition, the trochanteric epiphysis when left intact produces a tendency for the leg to adduct with growth. The graft remoulds with growth (Fig. 6).

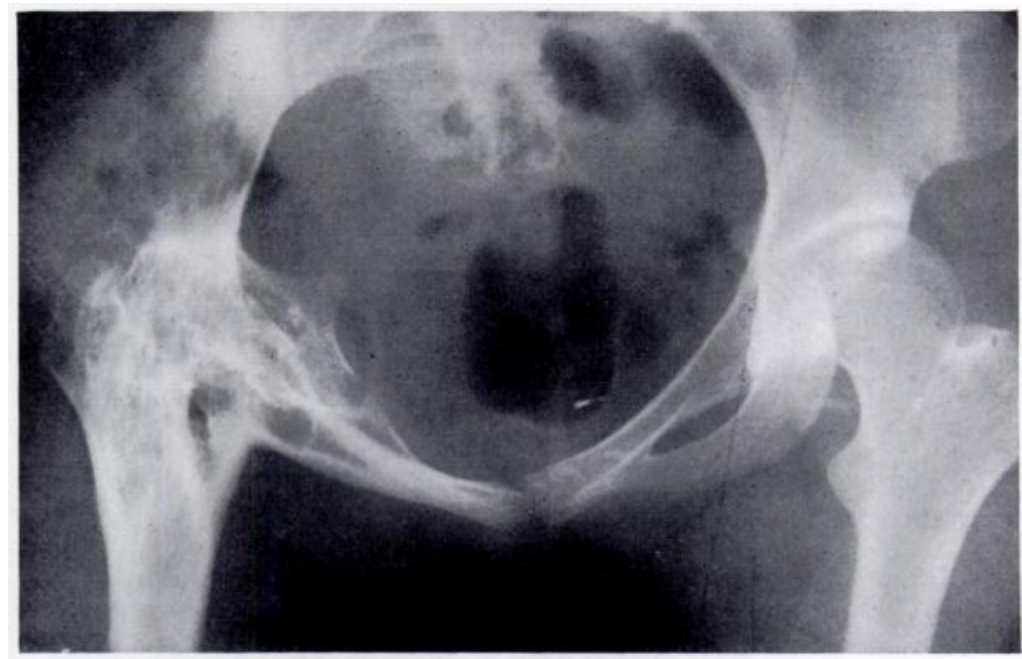

FIG. 6

Radiograph of girl's pelvis taken some years after osteotomy and graft at the age of eleven. Note the obliquity of the graft caused by growth at the trochanteric epiphysis.

After-treatment-The patient is kept in a double hip spica for one month, at the end of which the plaster is removed from the sound leg. At two months, if there are signs of good callus formation at the osteotomy site, the foot on the affected side is released. When there is good muscle tone the patient is allowed to walk in a single long hip spica. After the third month the plaster is replaced by a short reinforced leather or polythene hip spica which extends from the lower ribs above, to just above the knee below. This is worn continuously for a further month after which it is left off at night but worn during the day. It is discarded when the union is deemed sound. This is usually ten months to a year after the first operation. Treatment with anti-tuberculous drugs was continued on average for three and a half months after osteotomy.

\section{RESULTS}

Solid fusion of the hip and union at the site of osteotomy was obtained in all but three patients. The average time from excision or drainage to the attainment of solid fusion as judged clinically and radiologically was thirteen months (range seven to twenty-six months).

The three patients who developed pseudarthrosis at the site of osteotomy all obtained good function without pain. All had sinuses and involvement of the lungs before treatment was started. 
Shortening-Residual shortening varied from half an inch to two and a half inches. In sixteen cases it was less after the operations; in six it was more and in three it was unchanged. Disparity was reduced by amounts varying from one-quarter to two and a quarter inches; it was never increased by more than half an inch. It seems that reduction of the disparity must be a result of the interposition of the graft and the medial shift of the femoral shaft together with the stimulation of growth in the remaining epiphysis produced by the increased use following sound fusion.

Complications-In the immediate post-operative period two skin wounds broke down and one sinus recurred. The skin wounds healed after resuture but the sinus required further excision. At re-exploration a lateral pocket of tuberculous material was found. One patient developed a pleural effusion in the late post-operative period; one patient developed pneumothorax, and one a collapsed lower lobe following operation. All recovered after appropriate treatment.

Dangers of cancellous bone grafts-There is danger in trying to reduce the number of stages in the procedure and in trying to accelerate fusion by the addition of bone chips at the time of excision. No matter how old and quiescent the lesion may appear to be and no matter how carefully the excision may have been done, there is always the possibility that some diseased tissues may have been missed. In this event, subsequent breakdown is likely but it may be cleared by minor procedures. However, when bone chips have been used, healing never occurs until they are removed. When a sinus forms after bone chips have been used the only remedy is a complete re-excision.

\section{SUMMARY}

1. The results of treatment of twenty-five disintegrated tuberculous hips by excision, arthrodesis and anti-tuberculous drugs are reported.

2. The methods used are described.

3. Sound healing and bony fusion was obtained in all but three of the twenty-five hips treated.

We are indebted to the Director of Medical Services, Ministry of Health, Singapore, for permission to publish this paper.

\section{REFERENCES}

Aввотt, L. C., and Fischer, F. J. (1931): Arthrodesis of Hip. Surgery, Gynecology and Obstetrics, 52, 863. Aввotr, L. C., and LuCAS, D. B. (1954): Arthrodesis of the Hip by Wide Abduction in Massive Destruction of the Joint. Journal of Bone and Joint Surgery, 36-A, 1,097.

Brittain, H. A. (1942): Architectural Principles in Arthrodesis, pp. 32-37. Edinburgh: E. \& S. Livingstone Ltd. Girdlestone, G. R., and Somerville, E. W. (1952): Tuberculosis of Bone and Joint, p. 111. Second edition. London: Oxford University Press. 